\title{
Characteristics of Computational Thinking about the Estimation of the Students in Mathematics Classroom Applying Lesson Study and Open Approach
}

\author{
Siwarak Promraksa ${ }^{1}$, Kiat Sangaroon ${ }^{2} \&$ Maitree Inprasitha $^{3}$ \\ ${ }^{1}$ Faculty of Education, Khon Kaen University, Khon Kaen, Thailand \\ ${ }^{2}$ Department of Mathematics, Faculty of Science, Khon Kaen University, Khon Kaen, Thailand \\ ${ }^{3}$ Center for Research in Mathematics Education, Faculty of Education, Khon Kaen University, Khon Kaen, \\ Thailand \\ Correspondence: Siwarak Promraksa, Faculty of Education, Khon Kaen University, Khon Kaen 40002, Thailand. \\ Tel: 66-8-1662-1387. E-mail: spromraksa@hotmail.com
}

Received: May 20, 2014

Accepted: June 23, 2014 Online Published: July 17, 2014

doi:10.5539/jel.v3n3p56

URL: http://dx.doi.org/10.5539/jel.v3n3p56

\begin{abstract}
The objectives of this research were to study and analyze the characteristics of computational thinking about the estimation of the students in mathematics classroom applying lesson study and open approach. Members of target group included $4^{\text {th }}$ grade students of 2011 academic year of Choomchon Banchonnabot School. The Lesson plan used for data collection in this research was developed according to lesson study and open approach on the subject of estimation, which included Activity no.1 "How many notebooks would we get?" and Activity no.2 "How many trains would be needed?" Results of the research showed that the students were able to present their characteristics of computational thinking about the estimation according to the 4 steps of open approach as well as to obtain a theoretical framework of computational thinking levels about the estimation of the students in mathematics classroom applying lesson study and open approach. Considering the thinking levels of the $4^{\text {th }}$ grade students of 2011 academic year of Choomchon Banchonnabot school, it showed that: the characteristics of computational thinking about the estimation of the students in mathematics classroom applying lesson study and open approach had included all levels of theoretical framework of thinking levels about the estimation of the students in mathematics classroom with lesson study and open approach, and that the thinking process about the estimation of the students in mathematics classroom using lesson study and open approach would use the reformulation of estimation before computation and estimation after computation.
\end{abstract}

Keywords: computational thinking about the estimation, problem solving, lesson study, open approach

\section{Introduction}

Learning content and standard about numbers and the process in accordance with the basic education core curriculum 2008 emphasized on the importance of teaching the contents of numbers and operations at all levels in order to enable the students to understand the use of numbers and operations, the results of operation of number, the relations between various operations, the use of operation to solve problems, the ability to use estimation and solution, as well as to understand about number system and the use of properties of the number (Ministry of Education, 2008), according to the National Council of Teachers of Mathematics [NCTM] (2000) that said "Instructional programs, from kindergarten through $12^{\text {th }}$ grade, should enable all students to understand numbers, understand meanings of operations and how they relate to one another, compute fluently and make reasonable estimates." Further, NCTM (2000) acknowledged the role of estimation "as an important companion to computation" and as "a tool for judging the reasonableness of calculator, mental, and paper-and-pencil computations".

As a result of the changes in societal needs, mathematics education reform in Thailand have recommended that school mathematics curricula include topic on estimation. NCTM (2000) acknowledged the importance of developing students' ability to estimate: Students should develop and adapt procedures for mental calculation and estimation. Mental calculation and estimation are also useful in many calculations would help the students to understand better about number and would be able to think flexibly about the number. Furthermore, NCTM 
(2000) recognized the necessity of developing students' flexibility in using various computational techniques and students' judgment on the choices of different computational strategies appropriate for the situation: "Part of being able to compute fluently means making smart choices about which tools to use and when. Students should have experiences that help them learn to choose among mental computation, paper-and-pencil strategies, estimation, and calculator use".

"Part of being able to compute fluently means making smart choices about which tools to use and when". (NCTM, 2000) From the phrase "which tools to use and when", it could be seen that Thailand has applied lesson study and open approach since 2002. The trial of lesson study and open approach has been started in one of the primary schools in a Khon Kaen province. It showed that the change made to mathematics classroom has given the opportunity to the students to participate in learning activities. In year 2006, the Center for Research in Mathematics Education (CRME), Faculty of Education, Khon Kaen University proceeded with the trial learning program for mathematics classroom with lesson study and open approach with the whole school approach. It could be mentioned that the use of school as a base for continuing development with the application of lesson study and approach has raised the quality of the classroom (Inprasitha, 2010b).

Learning activities for the lesson study in Thailand has been operated under 3 phases: 1) Collaboratively Design Research Lesson: Plan 2) Collaboratively Observing the Research Lesson : Do and 3) Doing Post-discussion or Reflection on Teaching Practice: See (Inprasitha, 2010a). Lesson Study is a term for a system of professional development for teachers in Japan, called Jugyokenkyu (Jugyo refers Lesson and Kenkyu refers Study or Resarch) the Jugyokenkyu refers to study or research on the practice of teaching (Fernandez \& Yoshida, 2004). Researchers and educators to provide meaningful Lesson Study varies as Lewis (2002) stated that Lesson Study is a cycle in which teachers work together to consider their long - term goals for students, bring those goals into life in actual "research lesson" and collaboratively observe, discuss, and refine the lessons, Wang-Iverson \& Yoshida (2005) stated that Lesson Study as a form of teacher professional learning in the long run by a teachers, developed in Japan by the teachers doing their researches on teaching and learning in the class together with students for variety of experiences learning and improve the teaching of their own, Isoda, Stephen, Ohara, \& Miyakawa (2007) stated that Lesson Study came to be known around the world as a uniquely Japanese method of lesson improvement which is designed to facilitate the development of a high quality lessons, Baba (2007) stated that Lesson Study refers to the process that the teachers attempts to improve how their teaching by working together with other teachers. To review and critique the teaching techniques of each other, Thinwiangthong (2012) stated that Lesson Study is a process for teacher professional development by teachers in schools to improve the quality of instruction and student's learning.

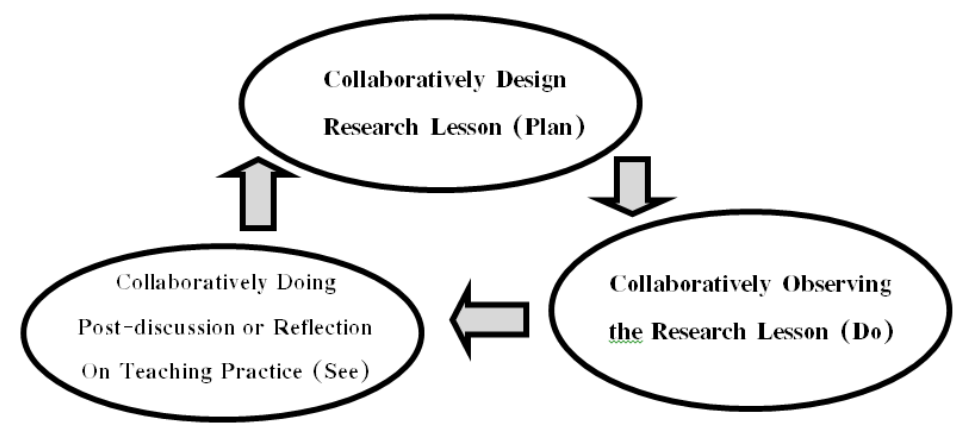

Figure 1. Three phases of lesson study (Inprasitha, 2010a)

Followed by integrating the lesson study with the open approach, which included 4 steps: 1) Posing Open-Ended Problem 2) Students' Self Learning 3) Whole Class Discussion and Comparison 4) Summarization Through Connecting Students' Mathematical Ideas emerged in the Classroom (Inprasitha, 2010a). Open Approach is an innovation that was developed in the 1970s (1970-1980) in Japan. Development of classroom research about lesson study to develop new teaching approaches, which is classified as an open process (There are many ways to solve the problems), the open results (with many answers to solve open-ended problems) and open problems (changes and develop new problem from the origin). At a later time Nobuhiko Nohda be integrated open-ended problems and Lesson Study as a way of new teaching called "open approach" (Isoda, 2007). In the 1970s 
(1970-1980) and (1980-1990) open approach as a way to reform the teaching of mathematics classes in Japanese. Published worldwide (Inprasitha, 2006) that teaching using open approach to all students can learn mathematics response their abilities coupled with their decision making on their own learning. Expanding the quality of the process and consequences on the mathematics (Nohda, 2000).

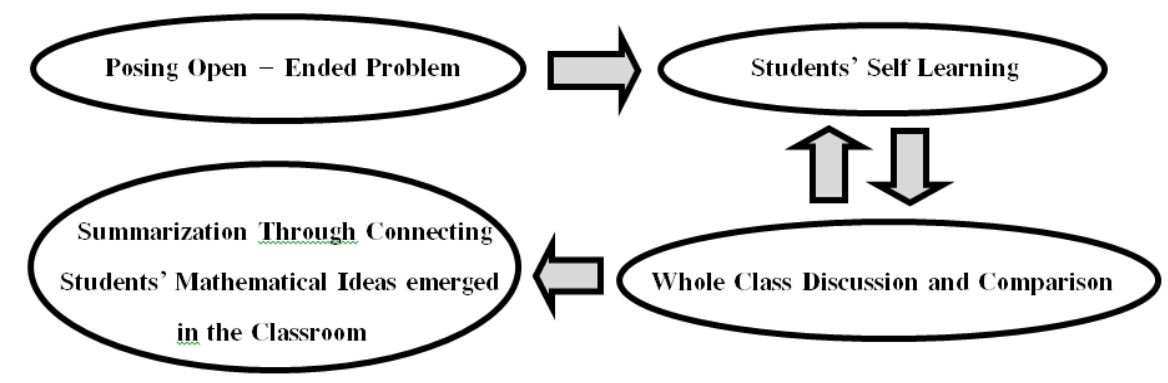

Figure 2. Four stages of open approach (Inprasitha, 2010a)

Lesson study and open approach would help the students to be able to present that ways to solve mathematical problems according to their nature of thinking and experiences that would lead to essential concepts in solving problems.

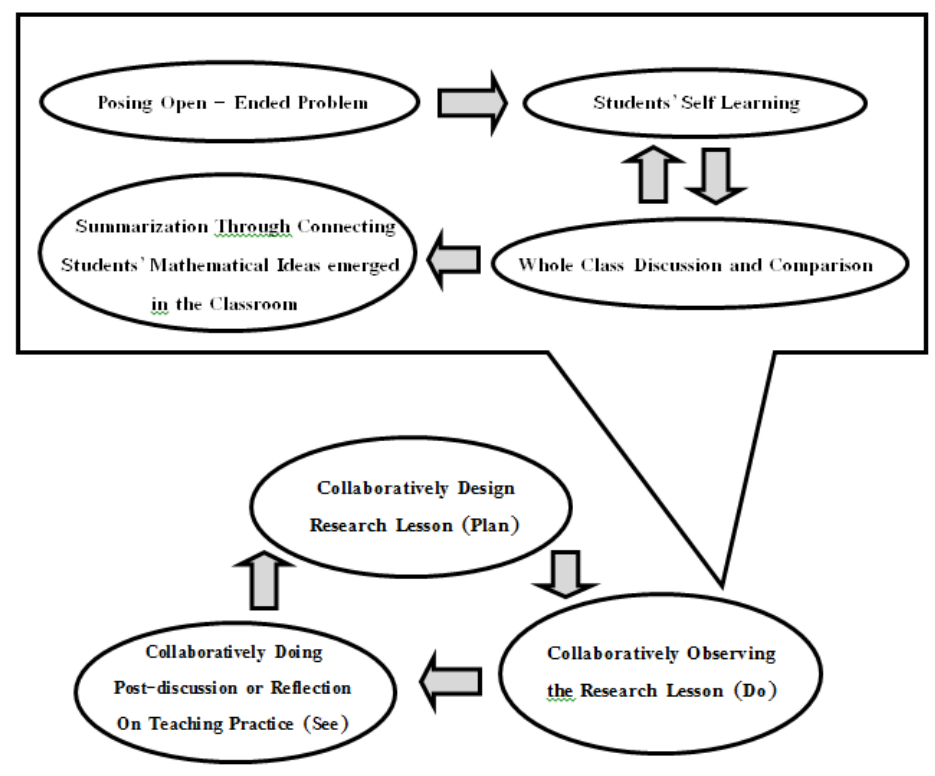

Figure 3. Lesson study and open approach (Inprasitha, 2010a)

For this research of characteristics of computational thinking about the estimation of the students from mathematics class that applied lesson study and open approach, the studying context was Choomchon Banchonnabot school, a primary school in the Chonnabot district of Khon Kaen, one of the model master schools where lesson study and open approach in mathematics classroom have been applied by joining the Teacher Professional Development project, which was organized by the Center for Research in Mathematics Education, Faculty of Education since 2006.

To conduct the process of Lesson Study and Open Approach, the teacher of $4^{\text {th }}$ grade, the researcher, the assistants and the student teachers in the school had joined to design and plan the lesson, observe of teaching, discuss and reflect the findings together, respectively. The mathematics classroom was designed with the lesson 
plan that focused on solving problems with open approach, with the objectives to enable the students to participate in each of all 4 steps of open approach procedure. In this research, the researcher has taken the work of the students and the class discussion in solving problems, which was in a form of protocol for analyzing the empirical data of the class, to answer the question of "How was the characteristics of computational thinking about the estimation of the students in mathematics classroom that applied lesson study and open approach".

\subsection{Objectives}

To study and analyze the characteristics of computational thinking about the estimation of the students in mathematics class which applied lesson study and open approach.

\subsection{Conceptual Framework}

The conceptual framework used in this study included (1) lesson study and open approach (Inprasitha, 2010a). Lesson Study meant the learning program to develop mathematical thinking of the students with 3 phases. Open approach meant the teaching that focused on solving open-ended problems, with the situations that were designed to encourage the students to solve mathematical problems on their own, which included 4 steps (Inprasitha, 2010a); (2) Neo-Piagetian conceptual framework of Case (1996). Early work of Piaget (1975) laid the foundation for the theory of development of children's thinking. Piaget's work was extended and refined by neo-Piagetian theorists (e.g., Biggs, \& Collis, 1991; Halford, 1980; Case, 1996), who proposed models of cognitive development that describe children's thinking in any knowledge domain. In particular, Case used the notion of central conceptual structure as a basis for theorizing cognitive development. Following Piaget, Case defined central conceptual structures as networks of semantic nodes and relations that regulate students' thinking in a particular knowledge domain (Case, 1996).

In 1996, Case put forth a theory of cognitive development with regard to quantitative thought. According to this theory, children's cognitive growth proceeds through four stages: the sensorimotor stage: approximate ages 0-1

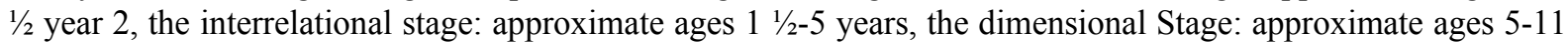
years and the vectorial stage: approximate ages 11-19 years, and each stage consisted of 4 thinking levels: 1) Predimensional 2) Unidimensional 3) Bidimensional 4) Integrated Bidimensional (Volkova, 2006).

\section{Methods}

This Qualitative Research of thinking levels and thinking process about the estimation of the students in mathematics class which applied lesson study and open approach would be performed by: 1) analyzing thinking process about the estimation of the students in mathematics classroom that applied lesson study and open approach, using qualitative research that focused on observation, videotape analysis, supported by protocol and analytical description. 2) assessing the thinking levels about the estimation of students in mathematics classroom that applied lesson study and open approach 3) creating a theoretical framework about the estimation of the students in mathematics classroom that applied lesson study and open approach.

\subsection{Participants}

The participants were $4^{\text {th }}$ grade students of 2011 academic year of Choomchon Banchonnabot School. Their age ranged from 9-12 years old. They are familiar with mathematics classroom adapting Lesson Study and Open Approach. They voluntarily participated in this study.

\subsection{The Study Was Divided into 2 Phases}

Phase 1: Studying context, feasibility of conducting the research, and Neo - Piagetian conceptual framework of Case (1996).

Phase 2: Creating theoretical framework of thinking levels, and analyzing characteristics of computational thinking about the estimation by the students in mathematics class that applied lesson study and open approach, by using 2 lesson plans developed according to lesson study and open approach about the computational estimation of $4^{\text {th }}$ grade class: Activity no.1 "How many notebooks would we get?" and Activity no. 2 "How many trains would be needed?" The class was instructed by student teacher, and observed by the teacher of the $4^{\text {th }}$ grade. The $1^{\text {st }}$ research assistant recorded the videotape of the whole classroom and recorded: the conversation between the teacher and the students, among the students; classroom discussion and presentation of students' work. The $2^{\text {nd }}$ research assistant recorded the videotape for only target group, took the photos of students' paper work during the activities, class discussion/presentation of students' work. The researcher took still shots with a camera and recorded the voice of the target group with a tape-recorder.

Data analysis was performed to analyze the problems-solving behavior of the students on computational thinking about the estimation, using synthetic description under the conceptual framework of learning activities, 
instruction in mathematics class using open approach (Inprasitha, 2010a). Each period of the class would comprise the same structural learning activities. Protocol analysis of the data collected from 2 periods of class was conducted to review the characteristics of computational thinking about the estimation of the students, following by the analysis of characteristics of computational thinking about the estimation of the students in mathematics classroom applying lesson study and open approach.

\section{The following were the results:}

\section{Activity 1 "How many notebooks would we get?"}

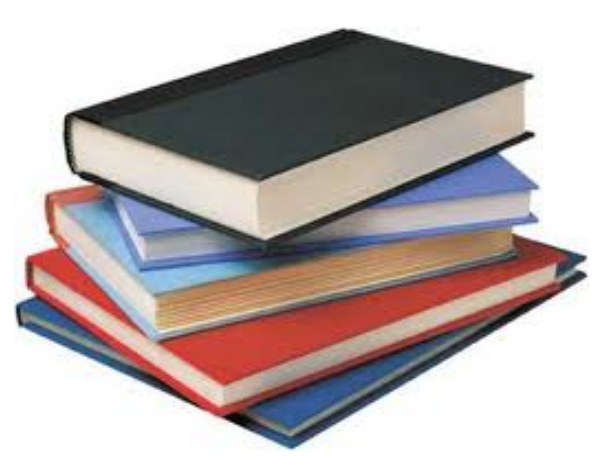

\section{Mathematical problem:}

"If the teacher would make the notebooks and one notebook would contain 100 sheets of paper.

If there were 876 sheets of paper, how many notebooks would we get?"

Figure 4. Notebooks the analysis performed by using 4 stages of open approach showed the following

\section{Step 1. Posing open-ended problem of Open Approach.}

The teacher commenced the class by placing the picture of mathematical problem on the board, and introduced the lesson with the problem that would encourage the students to participate in solving. The problem was about helping the teacher to make the notebooks. The instructional media included some A4 paper and 1 notebook. The teacher stimulated the students to help solving the problems which would enable them to learn and understand and to think about how to solve the mathematical problem.

\section{Step 2-3. Students' self-learning and Class discussion of Open Approach.}

The students have understood the mathematical problem of making notebook with 100 sheets of paper. The students would solve the problem and have class discussion to find the solution by means of dividing. The total number of sheets of paper divided by the number of sheets needed to make one notebook, which were 100. Since there were 876 sheets, they could make 8 notebooks and there were 76 sheets left which could not make another notebook as the number was less than 100 . The principle of estimation was that any number which was greater or equal 50 could be rounded up to 100 , and any number which was fewer than 50 would be rounded down to 0 . The conclusion of the students was "Based on the fact, they could make 8 notebooks. Based on the principle of estimation, they could make 9 notebooks. However, for this mathematical problem, they could not use the estimation, they had to base on the fact." 


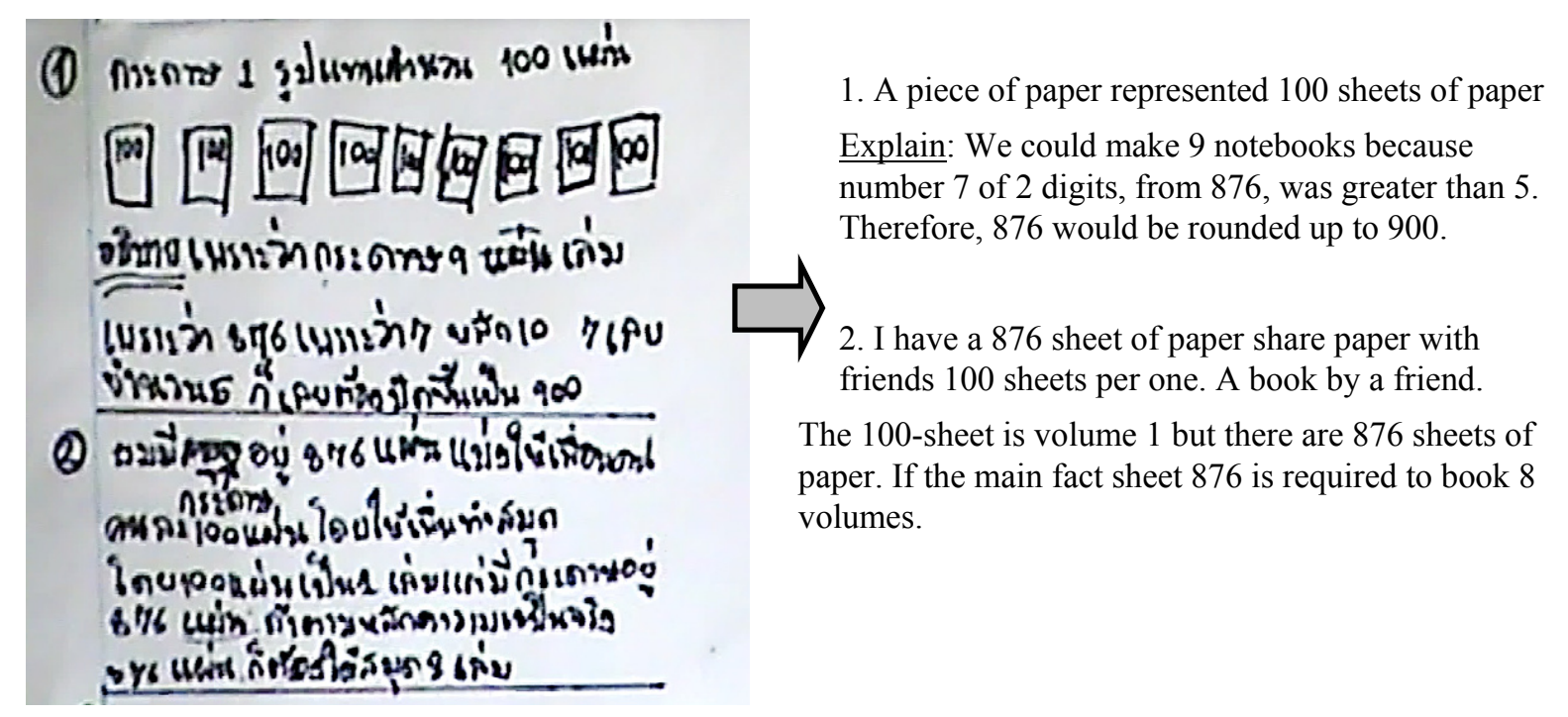

Figure 5. Students' paper work

\section{Step 4. Summarization Through Connecting Students' Mathematical ideas emerged in the Classroom.}

The students presented the results derived from class discussion, and the teacher would connect their concepts by questioning about their ways of thinking and understanding. The conclusion was made therefore that before using the estimation, they would have to consider what the problem was about, what was needed to be known or solved. The outstanding point of this situation, the students were able to compare the principle of the estimation and the fact which could be seen from their own conclusion that "Based on the fact, they could make 8 notebooks. Based on the principle of estimation, they could make 9 notebooks. However, for this mathematical problem, they could not use the estimation, they had to base on the fact."

\section{Activity 2 "How many trains would be needed?"}

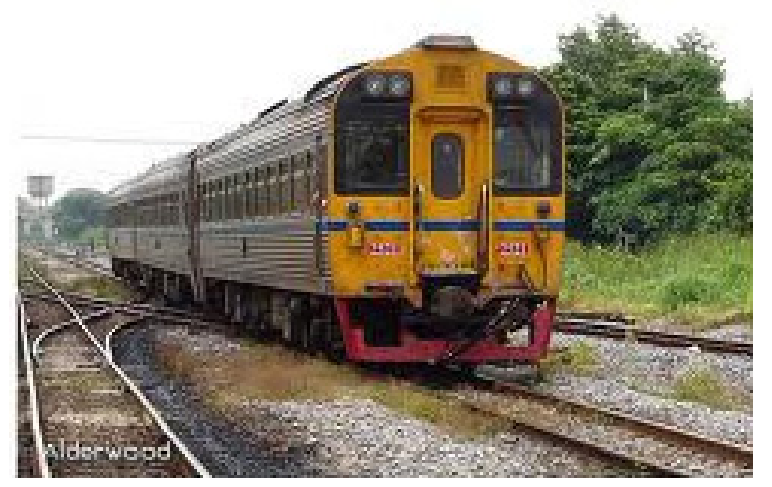

\section{Mathematical problem:}

"The students of Choomchon Banchonnabot school would arrange the field trip, and arranged to have 100 students travelled in each train. If there were 823 students, how many trains would be needed?"

Figure 6. Train

The analysis performed by using $\mathbf{4}$ stages of open approach showed the following.

Step 1. Posing open-ended problem of Open Approach. The teacher commenced the class by greeting the students and placing the picture of mathematical problem on the board, and introduced the lesson with the problem. The students showed the interest to solve this mathematical problem as they had experience with the problem from their last field trip about the number of students and number of buses, and they did not want to face the same problem again.

\section{Step 2-3. Students' self-learning and Class discussion of Open Approach.}

From the experience of having problem from last field trip, the students had class discussion to solve the problem in order to avoid the problem how to provide the number of students and number of buses. The 
mathematical problem was how many trains would be needed for 823 students. The answer of the student was 8 . The teacher asked why it was 8 , The students answered that it was because the number was 800 . The teacher asked what about the other 23 students when there were only 8 trains. The students replied that the 23 students would walk or the 23 students would sit too comfortably if there would be 9 trains. When they asked if it would be possible to not take the 23 students, the teacher said if you were one of those 23 , then you would not be able to join the trip. From that response, the concept of the students had been changed. Therefore, their answer was 9 trains because there were also 23 students. From what the students learnt and had class discussion, it created new concept for the students. They could compare the principle of estimation and the fact. The solutions of the students were "Based on the fact, they would need 9 trains for 823 students, as the $1^{\text {st }}$ train to $8^{\text {th }}$ train would accommodate 100 students each and the $9^{\text {th }}$ train would accommodate 23 students. Based on the principle of estimation, since 2 in 2 digits number was fewer than 5, therefore it would be rounded down to 800 which meant that 23 had to be taken out or that 23 students could not join the field trip because there would be no seat available for them. According to this the students replied that they would need 9 trains in order that all students could travel together or the 23 would be upset for not being able to join the trip if only 8 trains would be used.

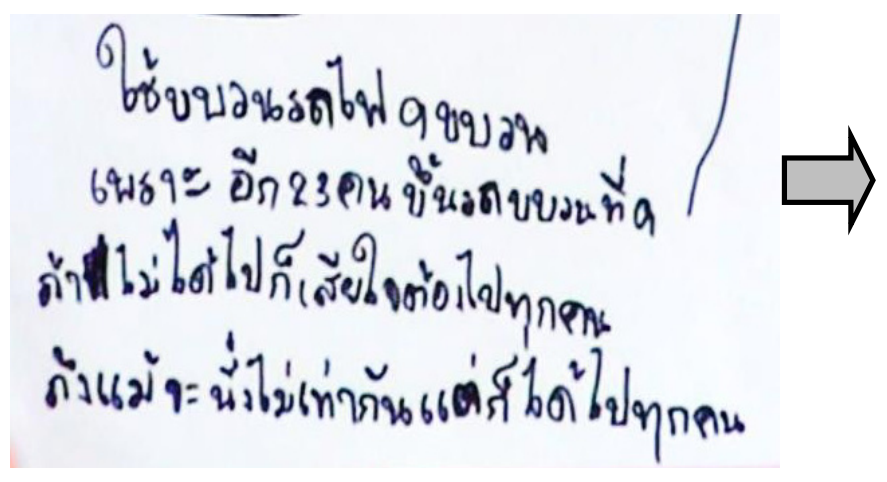

We would need 9 trains because the other 23 students could be on the 9 th train. If they would not be able to go, they would be unhappy. Everybody should be able to go. Despite that the number of the students in the train would be different, all could go.

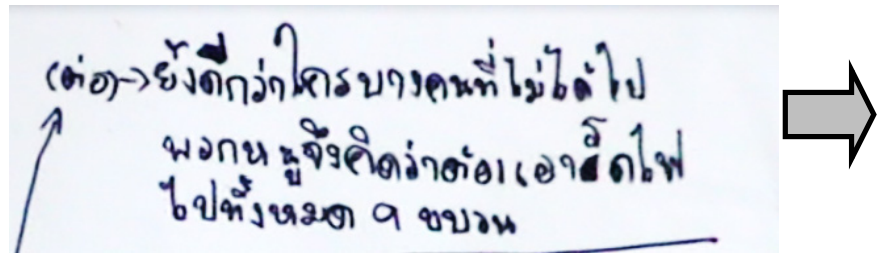

It would be better than some students would be left out. We thus had the opinion that we would need 9 trains.

Figure 7. Students' paper work

\section{Step 4. Summarization trough Connecting Students' Mathematical ideas emerged in the Classroom of Open-Approach.}

Based on Students' self-learning, it could be noticed clearly when the teacher asked "How many trains would be needed?" The students replied " 9 trains would be needed because the $9^{\text {th }}$ train would be for the other 23 ". The teacher asked "How many students were there in this situation?" The reply from the students was " 823 ". The teacher asked "What would be the estimation of 823?" The students said "For the estimation of 3 digits number, we would estimate from 2 digits number". The teacher asked "What was the 2 digits number?" The students answered "number 2 with the value of 20 which had to be taken out because it was fewer than 50". The teacher continued that "Based on the estimation, we had to rounded down the number to 800 and use 8 trains. But we could not if we would use 8 trains, the 23 students would be unhappy if they would not be able to join the trip. Therefore, we could not base on this estimate. How could we do to let this 23 students go with us?" The students said "We would take another train". The teacher said "That meant we had to round number 23 up to 100. 800 plus 100 equaled 900 . Thus, how many would be needed?" The students answered "9 trains". The teacher then summarized that "In this situation, we would round up the number because we would like all students to go together. But, in the previous situation of making notebooks from 876 sheets of paper, we would make 8 notebooks from 800 sheets of paper. Number 76 was supposed to be rounded up, but based on that situation, we could not". The conclusion was that before making the estimation, it needed to consider the situation to see what need to be known or solved. From this situation, it showed that there were many thinking ways for the 
estimation. It could be done by using the division, estimation by rounding up or down from what the students learnt from the lesson, or not using the estimation but the fact to solve the problems.

Characteristics of Computational thinking about the estimation on Activity no.1 "How many notebooks would we get?" and Activity no.2 "How many trains would be needed?" of the Students in Mathematics Class that applied study lesson and open approach.

Thinking Process about Estimation. Situation in Activity 1 "How many notebooks would we get?" The students would use the reformulation of estimation before computation. " 100 sheets of paper would be for 1 note book. Number 7 in 2 digit numbers was greater than number 5 should be rounded up to 900 to get 9 notebooks" And, the reformulation of estimation after computation. "876 divided by 100 equaled 8 with number 76 left which was fewer than 100, and would get 8 notebooks". Or Situation in Activity 2 "How many trains would be needed?" The students would use the reformulation of estimation before computation. "If there were 823 students, how many trains would be needed?" " 8 trains because the estimation number of 823 equaled 800 " And, the estimation after computation "Used the division, and got 8 with the fraction of 23 " which could be described that " 9 trains would be needed as 23 students would travel on the $9^{\text {th }}$ train. It would be need to take 9 trains to allow all students to join the trip, unless the 23 students would not be able to join and they would be unhappy" The adjustment of making the reformulation of estimation after computation for both activities would be considered as an integration because the estimation would not be relevant to the lessons but to the fact. Each fact or circumstance would be used to determine or solve the problem, like what the students said "For this mathematical problem, the estimation could not be used, had to base on the fact."

Thinking levels about the estimation from the students' answers on

Activity 1. "How many notebooks would we get?" One notebook contained 100 sheets of paper. 876 sheets of paper would make 8 notebooks with the fraction of 76 sheets, or on Activity 2. "How many trains would be used?" 8 trains would be used and 23 students would have to walk, showed that the estimation of the students in mathematic class was based on the computation to get exact answer. This would be ranged in level $\mathbf{1}$. Predimensional of the theoretical framework of thinking levels about the estimation of the students in mathematics class that applied lesson study and open approach.

Activity 1. "How many notebooks would we get?" According to the principle of estimation, 876 sheets of paper, 7 in 2 digits was greater than 5, the number should be rounded up to 900 and made 9 notebooks or Activity 2. "How many trains would be used?" for 823 students. According to the principle of estimation, 2 in 2 digits was fewer than 5 and got to be rounded down to 800 . Therefore, 8 trains would be used. I could be seen that thinking ways of students in mathematics class would be in accordance with what they acquired from the lesson in the class. This would be ranged in level 2. Unidimensional of theoretical framework about the estimation of the students in mathematics class that applied lesson study and open approach.

Activity 1. "How many notebooks would we get?" To make 1 notebook, 100 sheets of paper would be needed. With 876 sheets of paper, it would make 8 notebooks based on the fact. The remaining of 76 sheets would not make a book, as the number was fewer than 100. And, number 7 in 2 digits, of 876 sheets of paper, according to the principle of estimation was greater than 5 should be rounded up. Therefore, the number of the sheets should be rounded up to 900 , and should make 9 notebooks. The estimation could not be applied to this mathematic problem or situation, the fact had to be considered instead. Or Activity 2. "How many trains would be used?" 9 trains would be needed so that the 23 students would be able to travel on the $9^{\text {th }}$ train, unless the student who missed the trip would be unhappy. Thus, 9 trains should be taken, and the last train would accommodate 23 students. The outstanding point of this situation was the ability of the students to compare the principle of estimation and the fact. And, it could be seen even clearly with the answers of the students that "Base on the fact, 9 trains would be needed. Based on the estimation, 8 trains would be needed. However, in this situation, the fact had to be considered". From both activities, the students were able to use the integration of estimation in real life to determine the solution of the problem. This would be ranged in level 4. Integrated Bidimensional of theoretical framework of the students in mathematics class that applied lesson study and open approach.

The students used various ways of estimation, in level 1,2, 4, which could be ranged in level 3. Bidimensional of theoretical framework about the estimation of the students in mathematics class that applied lesson study and open approach.

The relationship of thinking levels and thinking process about the estimation, as per Activity no1 "How many notebooks would we get?" and Activity no.2 "How many trains would be needed?", of the students in mathematics class that applied lesson study and open approach. 
Level 1 Predimensional: The students would not use thinking process about the estimation, but would use the computation as per mathematical process that would give a certain and clear answer.

Level 2 Unidimensional: The students would use thinking processes about the estimation learning from the class for the estimation before computation or estimation after computation.

Level 3 Bidimensional: The students would use various thinking processes and with or without estimation process. Thinking process with the estimation would use the estimation before computation or estimation after computation. Thinking process without estimation would be computed with mathematical processes would give a certain and clear answer or would base on the fact in real life in finding solution.

Level 4 Integrated Bidimensional: The students would not use thinking process with the estimation, but their thinking process would base on the fact in real life or use the integration for solving problem.

The results of the study. It showed that the students were able to present their thinking abilities about the estimation in conformity with the following 4 steps of open approach.

Step 1. Posing Open-Ended Problem. The students would try to understand the problem of the situation, feel that it was their own problem, and want to solve the problem by on their own.

Step 2. Student's Self Learning. The students would learn to solve the problems on their own, be able to create ideas and methods from what they had learned to solve problems and have efforts to create various solutions.

Step 3. Whole Class Discussion and Comparison. This step was to examine and reflect the solutions of the problems together with classmates and the teacher.

Step 4. Summarization Through Connecting Students' Mathematical Ideas emerged in the Classroom. The students would get the ideas and effective methods to solve the problems easily and concisely, which could be used as knowledge and tool to solve other next problems.

The results derived from all 4 steps of open approach allowed the pertaining of theoretical framework of thinking levels about estimation of the students in mathematics class that applied lesson study and open approach as follows.

Theoretical framework about the estimation of the students in mathematics classroom that applied lesson study and open approach:

Level 1 Predimensional: The students would do the computation and get the exact result in accordance with mathematical process.

Level 2 Unidimensional: The students would use the reformulation of estimation before computation or estimation after computation.

Level 3 Bidimensional: The students would take various thoughts, both with and without thinking process of estimation. If thinking process of estimation were used, the reformulation of estimation before computation or estimation after computation derived from class would be conducted. If thinking the processes of estimation were not used, the computation with certain results according to mathematical processes would be conducted. Or the integrating principle might be used to solve the problems by taking the estimation of the fact in life to determine the problem solution of the estimation.

Level 4 Integrated Bidimensional: The students would not use thinking processes about the estimation. But, they would use the integrating principle to solve the problems by using the estimation from the fact in life to determine the problem solution of the estimation and the characteristics of computational thinking about the estimation of the students in mathematics class with lesson study and open approach.

Considering the thinking levels about the estimation of the $4^{\text {th }}$ graders from academic year 2010 of Choomchon Banchonnabot school in Khon Kaen province which included: Level 1 Predimensional, Level 2 Unidimensional, Level 3 Bidimensional, and Level 4 Integrated Bidimensional of theoritical framework about the estimation of the students in mathematics class with lesson study and open approach, and thinking process about the estimation of the students in mathematics class with lesson study and open approach, the reformulation of estimation before computation and estimation after computation would be conducted.

\section{Discussion and Conclusion}

Based on the results of this research, the following were found. 1) The significance of the estimation in learning management on the subject of number and operation. The estimation has had significant role along with the computation and has been used as a tool to determine the reasonability of the students that performed the mental 
math and the computation using paper and pencil. It helped the students to understand the number better and to think flexibly about the number. 2) Teaching with open approach that focused on solving problems in the classroom with all four steps promoted the opportunity and enhanced learning and problem solving process of the students as seen in their behaviors for solving problems in each of the following 4 steps. Step 1) Posing Open-Ended Problem. This would promote the opportunity and enhance the skills on listening and understanding of the students. Step 2) Students' Self Learning. The students would learn to solve the problems on their own, create the ideas and methods from what they have learnt, have the attempt to find ways to solve the problems. Step 3) Whole Class Discussion and Comparison. This step was to examine and reflect the solutions of the problems together with classmates and the teacher. Step 4) Summarization Through Connecting Students' Mathematical Ideas emerged in the Classroom.

Theoretical framework about the estimation of the students in mathematics classroom that applied lesson study and open approach: Level 1 Predimensional, agreement with Volkova $(2005,2006)$, Level 2 Unidimensional, agreement with Volkova (2005, 2006), Level 3 Bidimensional, agreement with Volkova (2005, 2006), Level 4 Integrated Bidimensional, disagreement with Volkova $(2005,2006)$

\section{Research Suggestion}

The following were the suggestions based on this research.

1) Problems solving of the students which could be seen clearly in step 3 of the Whole Class Discussion and Comparison would also base on each individual basic way of life. The teacher should have to consider this point as well, such as: on Activity 1 "How many notebooks would we get?" to make the notebooks with 876 sheets of paper. 8 notebooks would be made with 76 sheets left. Students might say " 76 sheets to be sold" or "76 sheets to be used for drawing" or "76 sheets to be used to make small notebook", and on Activity 2 "How many trains would be used?" to take 823 students. For 100 students per train, 8 trains would be used, with the fraction number of 23 . The students might say " 23 students would not go" or " 23 students could go on foot" or " 23 students could travel on the roof of the train" or " 23 students could travel by 2 pick-ups, one carried 12 and the other carried 11". But, when the teacher said that the 23 students might include the students in the classroom, it could mean that they might not be able to go neither. Then, the answer was changed to " 9 trains in order to be able to go altogether".

2) Theoretical Framework. Thinking levels about the estimation of the students in mathematic classroom that applied Lesson Study and Open Approach could be applied for other types of thinking levels.

\section{Acknowledgements}

The first author would like to express sincere gratitude for the Ph.D scholarship from the Office of the Higher Education Commission, Ministry of Education, the Center for Research in Mathematics Education, Khon Kaen University and Loei Rajabhat University, Thailand.

\section{References}

Baba, T. (2007). Japanese Education and Lesson Study: An Overview. In M. Isoda, M. Stephen, Y. Ohara, \& T. Miyakawa (Eds.), Japanese Lesson Study in Mathematics: Its Impact, Diversity and Potential for Educational Improvement (pp. 2-7). Singapore: World Scientific Publishing. http://dx.doi.org/10.1142/9789812707475_0001

Case, R. (1996). Reconceptualizing the Nature of Children's Conceptual Structures and Their Development in Middle Childhood. Monographs of the Society for Research in Child Development, 61(1-2), 1-26. http://dx.doi.org/10.1111/j.1540-5834.1996.tb00535.x

Fernandez, C., \& Yoshida, M. (2004). Lesson Study: A Japanese Approach to Improving Mathematics Teaching and Learning. Mahwah, New Jersey: Lawrence Erlbaum Associates, Publishers.

Inprasitha, M. (2006). Open-ended Approach and Teacher Education. Paper presented at The Second APEC-Tsukuba International Conference on Innovative Teaching Mathematics trough Lesson Study II-Focusing on Mathematical Thinking. CRICED, University of Tsukuba.

Inprasitha, M. (2010a). One Frature of Adaptive Lesson Study in Thailand - Designing Learning Unit. In C. S. Cho, S. G. Lee, \& Y. H. Choe (Eds.), Proceedings of the $45^{\text {th }}$ Korean National Meeting of Mathematics Education (pp. 193-206). Korea: Dongkook University, Gyeongju. 
Inprasitha, M. (2010b). Project Report: Management Development of Academic Affairs in the Educational Institution Using the Innovation of "Lesson Study" and "Open Approach". Center for Research in Mathematics Education. Khon Kaen: Khon Kaen Printing.

Isoda, M. (2007). A Brief History of Mathematics Lesson Study in Japan. In M. Isoda, M. Stephen, Y. Ohara, \& T. Miyakawa (Eds.), Japanese Lesson Study in Mathematics: Its Impact, Diversity and Potential for Educational Improvement (pp. 8-15). Singapore: World Scientific Publishing. http://dx.doi.org/10.1142/9789812707475_0002

Isoda, M., Stephen, M., Ohara, Y., \& Miyakawa, T. (Eds.). (2007). Japanese Lesson Study in Mathematics: Its Impact, Diversity and Potential for Educational Improvement. Singapore: World Scientific Publishing.

Lewis, C. (2002). Lesson Study: A Handbook for Teacher-Led Improvement of Instruction. Philadelphia: Research for Better Schools.

Ministry of Education. (2008). The Basic Education Core Curriculum A.D. 2008. Bangkok: Ministry of Education.

National Council of Teachers of Mathematics. (2000). Principles and standards for school mathematics. Reston, VA: Author.

Nohda, N. (2000). Teaching by Open-Approach Method in Japanese Mathematics Classroom. In T. Nakahara, \& M. Koyama (Eds.), Proceedings of the 24th Conference of the International Group for the Psychology of Mathematics Education (PME24) (Vol. 1, pp. 39-53). Hiroshima, Japan: Hiroshima University.

Thinwiangthong, S. (2012). Small-group mathematical communication in classroom in lesson study and open approach context (Ph.D. Dissertation, Department of Mathematic, Khon Kaen University. Thailand).

Volkova, T. N. (2005, July). Characterizing middle school students' thinking in estimation. Proceedings of the 29th Conference of the International Group for the Psychology of Mathematics Education (PME29) (Vol. 4, pp. 289-296). Melbourne, Australia.

Volkova, T. N. (2006). Characterizing preservice teachers' thinking in computational estimation with regard with whole numbers, fractions, decimals, and percents (Ph.D. Dissertation, Mathematics Illinois state university, USA).

Wang-Iverson, P., \& Yoshida, M. (2005). Building Our Understanding of London Study. Philadelphia: Research for Better Schools.

\section{Copyrights}

Copyright for this article is retained by the author(s), with first publication rights granted to the journal.

This is an open-access article distributed under the terms and conditions of the Creative Commons Attribution license (http://creativecommons.org/licenses/by/3.0/). 